\title{
Between the Strategic Summit and the Operational Centre: An Organizational Analysis of the "Choisir de Gagner" Sport Project for Youth with Disabilities
}

\author{
${ }^{1}$ Julie Fortier, ${ }^{1}$ Estelle Nauroy, ${ }^{1}$ Marie-Eve St-Pierre, ${ }^{1}$ Romain Roult ${ }^{*},{ }^{1}$ Hélène Carbonneau \\ ${ }^{1}$ Université du Québec à Trois-Rivières (UQTR), Department of Leisure, Culture and Tourism, Trois-Rivières, Canada.
}

\begin{abstract}
Background. Choisir de Gagner is a Quebec (Canada) company associated to AlterGo and Défi sportif. Its mission is to promote a healthy lifestyle for youth with disabilities. Objectives. This article analyzes this organization, especially its strengths and weaknesses of its environments. Methods. The study took place over a three-year period, from 20122015. The first two data collections (2012-2013 and 2013-2014) aimed at analyzing the organization's internal components. In reference to these results, the third collection's goal (2015) was to analyze the transfer of knowledge that was developed during the organization's mandate. Results. Moreover, following the first data collection, a few weaknesses were identified regarding time management and the decision-making process. With regard to these results, certain adjustments were made in the organization which have led to a considerable improvement if we rely on the results from the second data collection. At the end of the article, the organization's external communication is specifically examined by an analysis of the transfer of knowledge. Several tools have been elaborated by the organization between 2012 and 2015. Conclusion. The main issues with respect to these tools are the respect and follow-up of each stage of the transfer process in order to ensure its sustainability.
\end{abstract}

KEY WORDS: Organization, Management, Evaluation, Transfer of Knowledge, Healthy Lifestyle, Physical Activity.

\section{INTRODUCTION}

The objective of the three studies presented here is to analyze certain environmental dimensions of Choisir de Gagner. The article is divided into two sections. The first examines the components of the internal environment (studies $1 \& 2$ ) and the second the transfer of knowledge (study 3) developed by the organization. The aim of this article is to analyze the strengths and weaknesses of a concrete case, anchored in its environment, whose mission is focused on the promotion of healthy lifestyles for young people with functional limitations.
According to the Quebec study on activity limitations, chronic diseases and aging 20102011, conducted by the Quebec Institute of Statistics (1), the disability rate observed among the Quebec population of 15 year-olds and over is $33.3 \%$, which corresponds to approximately 2206300 people. Among these, 1504500 have a mild disability and 710700 have a moderate or severe disability. Among the 15-24 year-olds, the disability rate is $24.3 \%$, which corresponds to 238700 people (1). Inspired by the World Health Organization, the study (2010-2011) defines the

*. Corresponding Author:

Romain Roult

E-mail: romain.roult@uqtr.ca 
concept of disability as a limitation of activities arising from a condition or a physical or mental health problem. These disabilities have an impact on peoples' daily lives; on their current activities, as well as on their social roles such as: education, work or sports and leisure activities.

Healthy lifestyles have a considerable influence on youth's health and their physical and mental development. They affect several aspects of an individual's overall health, i.e. eating habits, leisure and transportation activities, weight, body appearance and weight-related action; the use of cigarettes, alcohol and drug use; sexual behaviour (2). If we look at physical activity and eating habits specifically, the Quebec School Health Survey 2010-2011 (2), found that 70\% of high school students do not participate in enough physical activities and $67 \%$ did not consume the five daily servings of recommended fruits and vegetables. What about young people with disabilities? It is important to work with these young people to improve their quality of life. The Choisir de Gagner project also plays a fundamental role in healthy lifestyles (active lifestyle through sport and health eating) for young people between the ages of 5 and 21, who have a functional limitation by sensitizing the various partners to this effect.

\section{Description of the Choisir de Gagner organization.}

Choisir de Gagner is a project that stems from an Altergo ${ }^{1}$ and Défi sportif Altergo ${ }^{2}$ initiative and who benefited from the financial support of Québec en forme $e^{3}$ for a period of four and a half years (2012-2016). This project stands out by its mission which is centred on awareness of healthy lifestyles of young people aged 5 to 12 with a functional limitation. It then targets schools, rehabilitation centres and organizations in order to solicit their collaboration as partners. It also promotes universal accessibility to Québec en forme.

\footnotetext{
1 Altergo is in charge of various financial support programs to support its mission and to promote the social inclusion of persons with functional limitations by abolishing constraints to leisure, sports and culture (3).

${ }^{2}$ Défi sportif Altergo is an annual event organized by Altergo. It brings together athletes of all levels who have functional limitations of all kinds. This event's
}

In 2012-2013, Choisir de Gagner was under the control of the Deputy General Director of AlterGo and who is also the Director of Défi sportif. There are five employees: a development officer at special events; a sports program coordinator; a reception and special projects coordinator; a communications officer; and a Director. The following year (2013-2014), Choisir de Gagner had seven employees who were assisted by Altergo employees mobilizing around 20 staff members. In fact, AlterGo was part of the Choisir de Gagner team that divided into: Sports and logistics, Funding and Communication. Each of these teams consisted of a director and several coordinators.

The Choisir de Gagner project is, therefore, managed using a matrix structure articulating two lines of division of labour (Altergo and Choisir de Gagner). This method of managing, which is considered flexible, is seen as a process rather than a structure:

The matrix structure allows the organization to increase its flexibility and is capable of rapidly adapting to new situations. In addition, it promotes cooperation among the various units and emphasizes interpersonal relationships, decision-making and informational roles. However, its implementation is costly and creates a dual hierarchical channel that is confusing and may lead to divergent interests across divisions and functions that are concerned (6, p.283).

This definition identifies the advantages and disadvantages of this management process. The latter allows to manage the employees and the material resources in a vertical way, but she allows to manage the projects in a transverse way. This article presents the results of three studies aimed at analyzing the internal environment of the Choisir de Gagner organization and its

mission is to contribute to the social inclusion of athletes and to develop universal accessibility (4).

3 Québec en forme's mission is to "Mobilize individuals and all of Quebec society to act in favour of the adoption and maintenance of a physically activity and health eating lifestyle for the development of young Quebecers" (5). 
process of transferring knowledge to project beneficiaries, service providers and observers (7).

\section{Organization's internal environment}

Choisir de Gagner is an organization involved in healthy lifestyles, particularly in terms of accessibility to sports for young people with functional limitations. Since the analysis of the organization Choisir de Gagner is the foundation of this article, it then becomes pertinent to define the concept of "organization".

The organization was defined and summarized by different authors who had a somewhat similar vision. Here are some examples.

Whether it be large or small, public or private, for-profit or non-profit [the organization] possesses four main characteristics: 1) It has resources (human, materiel and financial) in order to provided goods and services; 2) It needs managers who will ensure the coordination, supervision and adequate integration and efficiency of these resources; 3) Every organization has a mission, since it exists for a precise reason; 4) The organization has a target clientele which must be determined beforehand (6, p.9).

According to another author (8), an organization is made up of six basic parts: 1) A key summit (the major choices; strategies); 2) The line of command (accessible means; tactics); 3) Operational centre (great achievements; operations); 4) Technostructure (refers to the flow of information); 5) Function of logistical support (resources and special units before a support function); 6) The organization's "ideology" (traditions and beliefs).

These authors who defined an organization (among others: 6, 8,9), describe the latter as an open system and indicate that systemic analysis can better understand and manage it. The analysis of systems "is based on the idea that in order to understand the functioning of everything, it is necessary to examine the links existing between the parts of this whole" $(6$, p.549).

Organizational diagnosis helps understand the strengths and eliminates weaknesses arising from the internal environment: internal stakeholders, management capacity and organizational culture (6). Organizational culture and entrepreneurship are in fact of the most important factors affecting organizational effectiveness (10).

Weaknesses of an organization's internal environment

The weaknesses of an internal environment may harm the development and functioning of an organizations. It is necessary to identify the possible causes for these weaknesses. Table 1 presents the causes for each of these components.

It is possible to add to this list the dimensions and criteria for organizational efficacity (11, p.25). With regard to dimensions, he identifies more specifically the value of human resources: the mobilization of staff (degree of interest and effort provided); Staff morale (the extent to which work experience is positively assessed by the employee); Staff performance (quality or quantity of output per employee or per group); Staff development (the extent to which competencies are growing among members of the organization). Human resources are at the heart of every organization. Their feeling of belonging, their motivations, their performance and their competencies remain essential for an organization's evolution. Moreover, a study led with non-profit sport entities demontrates the potential positive impact of management by values and the need to proactively engage employees within the process of managing values in these organizations (12). The results from our study show this importance.

\section{Transfer of knowledge}

The third study with regard to the transfer of knowledge has helped to better understand a component of the external environment and the transfer of knowledge. Knowledge management processes (acquisition, creation, storage, sharing, and application of knowledge) and entrepreneurship processes (idea creation, opportunity discovery, and idea exploitation) play an essential role in the strengthening of sport organizations (13). It is then relevant to define this concept.

Despite the nuances regarding definitions of the transfer of knowledge (14), it is possible to identify certain recurring elements. It is a process which aims to collect and share knowledge in order to facilitate access to essential information, possibly held by a minority, for the future use of all. The transfer of knowledge requires the willingness of a group or an individual to work 
with others and to share their knowledge for the purpose of a common benefit. Without this sharing, it is almost impossible to transfer the knowledge to another person (15). It is a question of exchanging knowledge (16). This exchange is defined as the set of steps taken to circulate knowledge among the people who need it or who are interested in it.

Table 1. Causes for weaknesses in an organization's internal environment (6)

\begin{tabular}{|c|c|}
\hline Internal environment & Causes for weaknesses \\
\hline Internal stakeholders & 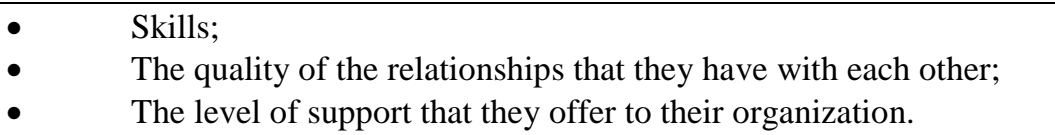 \\
\hline Management capabilities & 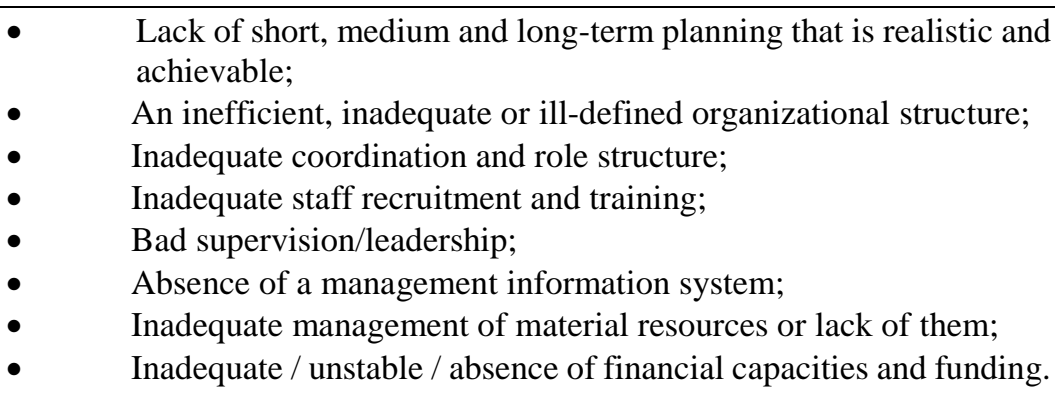 \\
\hline Organizational culture & $\begin{array}{l}\text { Level of individual autonomy; } \\
\text { - } \\
\text { A structure which would harmonize employee behaviour } \\
\text { (presence of rules, regulations and supervision); } \\
\text { Support and level of cohesion; } \\
\text { - } \quad \text { Identification with the company by the employee rather than his / } \\
\text { her position only; } \\
\text { Management of bonuses related to results; } \\
\text { - } \quad \text { Conflict tolerance; } \\
\text { Capacity to accept risks. }\end{array}$ \\
\hline
\end{tabular}

In addition, there are two types of knowledge: explicit and tacit. Explicit knowledge refers to objective and formal knowledge that can be verbalized, written, codified and transferred (e.g., books, directories, guides, policy handbooks and procedures, databases, etc.) (17). Tacit knowledge is more difficult to express and explain because it is personal and context-specific (judgment, know-how, well-being, values and intuitions $(15,17)$.

The transfer of knowledge can be defined as a bidirectional dynamic process which takes place between those who share their knowledge and those who need it (17). Seven steps in the transfer of knowledge are presented $(18,19)$. Three of these steps are part of the dissemination strategy: production, adaptation and dissemination. The other four steps are part of the development strategies: acceptance, adoption, development and use of knowledge. Here is a brief description of these steps:

Production consists of creating, generating, mobilizing or choosing pertinent knowledge of an object or a specific question in order to give it meaning.

Adaptation. There must be an adaptation of the content if the knowledge product, initially conceived for the public, has to be transferred to other audiences.

Dissemination. This is the "the process by which a knowledge product is communicated, for a certain period of time, through different communication channels such as media and interpersonal communication".

Acceptance of knowledge "refers to the context in which knowledge is transferred as well as the capacity and interest of potential users to receive this knowledge". 
Adoption is "the process by which a user, after having been in contact with the new knowledge, decides whether or not to adopt it".

Development refers "to the process whereby a person assimilates new knowledge or a new way of designing a problem and integrating this into his bank of knowledge, expertise and know-how".

The use of knowledge occurs in four dimensions: 1) conceptual (knowledge brings a new perspective to the problem or makes it possible to deepen the understanding of a problem; 2) instrumental (knowledge is directly used to make a decision or to develop a framework; 3) symbolic or strategic (knowledge is used to build an argument which justifies the action); 4) procedural (the actors involved in the research acquire knowledge during the process which they can then use). It is important to favor a participatory approach in identifying the issues of the use of the knowledge phase (20). Here are the important elements to consider in this step according to these authors:

(a) the source of surveillance data should be credible and involve potential users early in the research process; (b) the content of surveillance data should be accessible, adaptable, and sound; (c) the medium of transmission should be tailored and have multiple sources; (d) the user should be supported in knowledge acquisition and the implications of change implied by the data; and (e) the context of use can provide incentives and leadership in utilization (20, p.166).

In this study, we focused on the steps related to the knowledge appropriation strategy (acceptance, adoption, appropriation, use), since they are managed by external actors.

Successful transfer of knowledge depends on the availability and accessibility of knowledge (15). In addition, the knowledge being transferred should be useful and not only pertinent to know (20). However, the process of transferring knowledge may be limited by different barriers. There are three types of barriers to transferring knowledge: 1) individual barriers (ex.: linked to the transmitter's communication capabilities, motivation and integration capacities and receiver retention, etc.); 2) organizational barriers (ex.: linked to resistance to change, lack of resources, time constraints, etc.); 3) technological barriers (ex.: linked to data banks, technological tools, etc.) (21).

The individual and organizational barriers seem to play an important role in the limitation of the transfer of knowledge.

This article proposes an analysis of an organization with specific characteristics (funded by Québec en forme over a period of 4 years, who is part of other organizations, a matrix management structure, etc.) using Mintberg's organizational vision (basic parts of an organization) and Bergeron's environmental components and causes for weaknesses.

\section{MATERIALS AND METHODS}

The study took place over a three-year period, from 2012-2015. The first two data collections (2012-2013 and 2013-2014) aimed at analyzing the organization's internal components. In reference to these results, the third collection's goal (2015) was to analyze the transfer of knowledge that was developed during the organization's mandate. During this study, measures were taken to respect the confidentiality and anonymity of the research subjects. In addition, the free and informed consent of participants was ensured through the use of a presentation page and a consent form preceding the questionnaire.

Analysis of the internal organization (2012-2013 and 2013-2014). Two data collection periods were conducted for the study of the Choisir de Gagner's internal processes. The first one (2012-2013) used the collection of logbooks, completed weekly by the five stakeholders working on the project as its main method of collection. The second collection covers 2013-2014 and was conducted in the summer of 2014 with team members via four semi-directed interviews The contents of these journals and interviews were analyzed using a grid which identified the objects and steps; actors (internal and external); successes and learning; difficulties encountered; strategies used; affected parts of the organization (8); the environments (internal, immediate, general) (6); the organization's weaknesses; the causes for these weaknesses; the factors influencing these weaknesses (6). 
Analysis of the transfer of knowledge (2015). The analysis of the transfer of knowledge process (the tools) was done in the summer of 2015. The data collection was accomplished by way of a questionnaire which was distributed to the Choisir de Gagner team as well as to members of the advising committee, members of the Réseau du sport étudiant du Québec (RSEQ) Montérégie, members of the team working with Choisir de Gagner and to all professionals who, in the course of their duties, have used Choisir de Gagner's various services.

The questionnaire was composed of three areas of evaluation: level of the knowledge of the tools, level of use of these tools and the level of satisfaction with regard to the tools proposed by Choisir de Gagner. A few open questions have been added to this: the context of use, the tools that would be useful to develop, the means to favour the dissemination of the tools and the main benefits of the project.

A total of 80 people were contacted and 35 responded to the questionnaire, which represents a rate of $43.75 \%$. This is a weak response which limits our study. However, a majority of respondents shared the same opinion for a large part of the questions asked. This leads us to believe that the analyses may be considered valid. It is also important to note that a major part of respondents are stakeholders, who are the primary beneficiaries of the tools developed, which thus reduces the risk of bias.

\section{RESULTS}

This section presents the results of the evaluation of the Choisir de Gagner organization. First, the strengths and weaknesses analysis of the organization's internal environment will be presented. Then, the results from the evaluation of the transfer of knowledge from Choisir de Gagner to its partners will be discussed.

Analysis of the organization (2012-2013 / 2013-2014)

The first study conducted in 2012-2013 made it possible to distinguish the main factors that contributed to or hampered the operation and development of the Choisir de Gagner organization. Thus, from 2012 to 2014, the focus was on the internal environment. The presentation of these results is based on the elements of an organization's definition $(6,8)$.
Initially, an organizational diagnosis made it possible to identify the organization's strengths and weaknesses. Some obstacles hampered the functioning and development of Choisir de Gagner. With reference to Mintzberg (8), they apply to four of the six parts of the organization that are the operational centre (Choisir de Gagner stakeholders), the hierarchy (space between the stakeholders and Choisir de Gagner and AlterGo management), key summit (AlterGo) and ideology (of each organization). The matrix structure adopted by the Choisir de Gagner and AlterGo project ensures that the employees of Choisir de Gagner also work on the sports challenge managed by AlterGo.

\section{Internal environment}

A complex decision process

One of the main obstacles in Choisir de Gagner's internal environment concerns the hierarchy, that is to say, the two-way line joining the strategic summit, namely the management and the operational centre or intervenors. There were difficulties in communicating with management, lack of feedback, absence and corrections and approval delays that slowed the progress of files, particularly those with regard to the Choisir de Gagner project. These barriers make the coordination structure ineffective.

The decisional process, sometimes overlapping, seems heavy and complex. In this matrix structure, a type of management that was adopted by Choisir de Gagner, recognized for his complexity as a "confusing double hierarchy" $(6$, p.283).

The people who were interviewed noted an improvement, however, during the project (from 2012-2013 to 2013-2014) regarding the amount of delay and the complexity of the process. This improvement was noted by many as "successes". More precisely: "it takes more time for approval, but the process is simplified", "the approval was given" or "it is much better at the approval level".

The study conducted in 2012-2013 reveal difficulties of cohesion within the team. Interviews conducted in 2014 demonstrate a high degree of personal motivation for AlterGo employees to work on the Choisir de Gagner project, which contributes significantly to the working relationships and project development.

A lack of knowledge of the roles 
Another internal obstacle is concerned with the lack of knowledge of the roles of each person. This refers to a poorly understood organizational structure or an inefficient information system. The speakers mentioned that it is "difficult to specify who is doing what in the project" since there are several people involved. It is important, therefore, to understand each employee's role in the organizational chart, management staff (of AlterGo, and the Choisir de Gagner project), and operations staff. In fact, Choisir de Gagner's mission does not seem clear and shared by all stakeholders.

Managers must make strategic and operational decisions. According to the respondents, it is very important to distinguish between these two levels and to clearly establish the roles of each in such a way that the process is as efficient and effective as possible. It is also mentioned several times in the logbooks that it would be pertinent for there to be a specific management resource that would manage the more operational part of the project.

In 2014, the matrix model of management worked very well as compared to 2012-2013. There is, in fact, a consensus with regard to the proper functioning of this model. Modifications have been to this structure. Henceforth, the hierarchical structure separates the AlterGo organization into work teams in which the Choisir de Gagner program is fragmented. Each of the working teams (Sports and logistics, Financing or Communication), is composed of a Director and several coordinators. This success is due, in particular, to the willingness, motivation and sharing of a common vision on the part of the directors and the people in position. The interviews suggest that the team is more enthusiastic about this structure of work.

Between inefficient time management and relevance of meetings

First, all stakeholders noted the relevance and effectiveness of the team meetings. It was pointed out that they were productive and encouraged decision-making and, therefore, progress. Some meeting with all the stakeholders and the organization's leaders allowed for deliberation and decision-making with regard to the organization's real issued at that time which included: "who should be responsible for operations"; a fundamental issue in the management of an organization.
It may be noted that the coordination meetings favoured the integration and cohesion of the members, but later on in the deployment of the project. One person on the survey team said that it was more "integrated" following a coordinators' meeting which was held during the week of February 26, 2013. The deployment of the project began in September 2012, thereby leading us to reflect on the frequency of meetings and the discussion forum open to them, which promotes knowledge and recognition among the various members.

These meetings between the various players in the structure contributed to the mobilization of stakeholders. They have made it possible to question and understand and thus reduce doubts; obstacles for quality actions. However, in 2013, the multitude of planned meetings between project stakeholders was detrimental to time management and resulted in a lack of time to continue the tasks. The situation appears to have improved considerably during the second phase of data collection, both through fixed meetings and an adjustment to their progress. The interviews that were conducted in 2014 (one year later) reveal that the conduct at meetings, both at the operational centre (team meetings) and the strategic summit (coordination meeting) show a real team effort and seem to be appreciated by all. They are efficient and allow solutions to be found as soon as problems arise and help to advance priorities. In 2014, the directors succeeded in involving the entire organization in the Choisir de Gagner project.

As well, if the situation required it, it was possible for the team leaders to meet with the project director in order to discuss certain issues. However, the frequency of such meetings did not have everyone's support. Some people want to increase the frequency of encounters, while others prefer the opposite. The distribution of roles between the management of AlterGo and Choisir de Gagner also seems more precise in 2014.

In addition, the interviews indicated a good level of individual autonomy with regard to the tasks to be carried out and the mandates that were awarded. Within the management team, there is an openness to initiatives, new projects and new strategies.

Need for planned programming 
The Défi sportif plays a prominent role in the annual planning of stakeholders in 2012-2013. Many hours are invested in the preparation of this challenge, therefore, there is little time for the Choisir de Gagner project. It was noted in the logbooks that "She has not worked on the Choisir de Gagner project at all this week". In fact, once the challenge has taken place, the intervenors cannot, once again, work on the Choisir de Gagner project they are on leave since they accumulated time doing the event. Moreover, the team members are tired. The make-up of time means there are fewer to work, which in turn, makes for more work for those who remain.

Choisir de Gagner and the Défi sportif are seen as being complementary to each other, but this seems to generate an imbalance in actions and decisions. The Défi sportif took up a lot of the employees' time. By 2014, the Choisir de Gagner program seems to be better integrated into the tasks of the entire team. The search for a new project for planned programming was already underway to harmonize the timetables of all and to promote communication between the work teams (logistics, communication, financial). This was to document the tasks and steps to be taken to complete the projects. As programs and events grow, so does the need for an effective and userfriendly project for planned programming.

Capacity for conflict management

Among the causes of weakness in an organization's culture is intolerance in the face of conflict. Within Choisir de Gagner, there is an ability of the organization's actors to manage conflicts. In the logbooks, we talk about "disagreements regarding the logo", "small disagreements to manage during the "Défi sportif" and "uncontrollable people from the outside during the challenge". However, with reference to these same logbooks, these conflicts seem to have been resolved quickly and effectively through exchanges and discussion.

In 2014, working relationships are seen as harmonious at both the operational and strategic levels. The interviewees testify for the right to speak and the effectiveness of the meetings, as previously mentioned. There is a collaboration between the directors and coordinators or the employees of the operational centre (hierarchical line).
In 2012-2013, a problem had arisen over the frequent absences of employees. Interviews conducted one year later (2014) revealed a change in work schedules. As shown by some of the people interviewed, the work schedule can be either stable or flexible. Moreover, a visual tool makes it possible from now on to know who is present as well as their availability. This seems to have a positive effect on employee collaboration.

Organizational culture: Mission and objective

During the 2014 interviews, it was clearly mentioned by some respondents that the Défi sportif and Choisir de Gagner form a whole. They are difficult to isolate since Choisir de Gagner stem from the Défi sportif. Each has leverage on the other: Choisir de Gagner helps improve the Défi sportif while the Défi sportif is a showcase for Choisir de Gagner. The latter has also contributed to raising the number of school-aged athletes at the Défi sportif. In addition, the financial resources of the Choisir de Gagner program are important throughout the budget. This financial contribution seems salutary. In fact, Choisir de Gagner's financial resources have retained employees and their expertise within the organization. However, in practice, the distinction between the two appears problematic. This distinction is clearer in 2014, but is still fuzzy.

Communication for the organization's use

In 2012-2013, there seems to be a problem with communication within the organization as a whole, from the centre of operations to the strategic summit.

First of all, within the organization centre. The difficulty of working as a team is one of the obstacles noted in the logbooks. Although the meetings were considered relevant, two employees argued that teamwork remains "arduous and timeconsuming" and that it is tricky to "put pressure on others so that projects advance".

It is also stressed that "everyone works on their own and advances without consulting one another", which affects the sense of belonging and the mobilization of the participants in the organization (11) and inhibits a global vision of the project.

The matrix structure is perhaps involved in this lack of communication between actors, a condition for the foundation of teamwork. Although such a process "fosters cooperation among the various units and emphasizes 
interpersonal relationships and decision-making and information roles" $(6, \mathrm{p} .283)$, it seems to make this more complex. One person who was interviewed specifies that "communication within the project is more difficult since the challenge was brought back" or "... the matrix structure is sometimes difficult to manage for employees. Perhaps we should think of a resource that could manage the more operational side of the project".

Many stakeholders are often absent, as recorded in the logbooks. This aspect concerns the organizational culture and, more specifically, the structure of the organization to harmonize the employees' conduct. Is there supervision and presence of rules and regulations within the project? Are these regulations clear and understood by all?

Members of management, who are decisionmakers in the project, do not appear to react to requests for approval on time. They voice their opinion during the meetings, but the operation is already well under way. With reference to the comments made in the logbooks, the revision of the channels of communication between the decisionmakers in the strategic summit and those working in the operational centre should be put on the agenda.

The following table presents the main weaknesses of the internal environment of the organization as well as the brought improvements.

Table 2. Major weaknesses of 'Choisir de Gagner's internal environment and improvements made

\begin{tabular}{ll}
\hline \multicolumn{1}{c}{ Major weaknesses (2013) } & \multicolumn{1}{c}{ Main improvements (2014) } \\
\hline $\begin{array}{l}\text { Lack of integration and cohesion between the } \\
\text { members of the work team }\end{array}$ & $\begin{array}{l}\text { Involvement by the whole organization. Greater amount of } \\
\text { time for discussion during meetings }\end{array}$ \\
\hline $\begin{array}{l}\text { Too many meetings between the project's } \\
\text { stakeholders which affects time management }\end{array}$ & $\begin{array}{l}\text { Fixed meetings in the schedule and adjustment of the running } \\
\text { of these meetings } \\
\text { Division of AlterGo into working teams in which Choisir de } \\
\text { Gagner is split } \\
\text { Each working team is made up of a director and several } \\
\text { coordinators }\end{array}$ \\
$\begin{array}{l}\text { Lack of clarity in the division of the managers } \\
\text { roles (AlterGo and Choisir de Gagner) }\end{array}$ & $\begin{array}{l}\text { Implementation of a new tool to standardize the timelines for } \\
\text { everyone and to promote communication between the working } \\
\text { teams }\end{array}$ \\
\hline $\begin{array}{l}\text { Difficulty in planning tasks over the short, medium } \\
\text { and long-term }\end{array}$ & $\begin{array}{l}\text { Review of the hierarchical structure (work teams : logistics, } \\
\text { communication, financial) }\end{array}$ \\
\hline $\begin{array}{l}\text { Difficulties in communicating with management, } \\
\text { lack of feedback, absenteeism and delays in } \\
\text { correction and approval }\end{array}$ & $\begin{array}{l}\text { Simplified process and greater availability of leaders } \\
\text { Misunderstanding of each other's roles }\end{array}$ \\
$\begin{array}{l}\text { Difficult communication within the organization } \\
\text { due to the pace and work methods of each } \\
\text { stakeholder }\end{array}$ & $\begin{array}{l}\text { between directors, between directors and coordinators, and } \\
\text { between coordinators and stakeholders }\end{array}$ \\
\hline
\end{tabular}

Analysis of the transfer of knowledge

Communication with external actors: An analysis of the transfer of knowledge

After analyzing Choisir de Gagner's internal environment during the first two data collections, we are now interested in the study of external communication by means of an analysis of the transfer of knowledge, in particular, of the tools created throughout the project. Some authors stress the importance of carrying out more empirical research with regard to the transfer of knowledge (20). In the case being studied, this transfer is made to the various actors involved in the Choisir de Gagner project, including schools, rehabilitation centres, advisory committee members and StudentAthlete Association of Quebec.

The tools developed by the Choisir de Gagner project are used, for example, in the training of project partners or in specific workshops with community organizations. In addition, these tools are used in the context of education, in the school environment and in the context of rehabilitation awareness. They are used to provide a "plus" with 
regard to services for members as well as for promoting the project to families and young people.

Here are the steps and strategies involved in the transfer of knowledge $(18,19)$ that were used by Choisir de Gagner. Steps related to the appropriation strategy were further explored in this study: acceptance (the actual and desired knowledge of the tools disseminated by the participants); adoption, appropriation and use, more complex to measure, by which we measured the frequency and context of the use of tools and by the level of satisfaction of the tools. We also asked participants about their appreciation of the benefits of the Choisir de Gagner project. This rather descriptive analysis helps us to understand the process of the transfer of knowledge and gives us examples of tools designed and transferred by the organization.

\section{Dissemination of tools}

Many tools have been developed and several actions have been implemented by the Choisir de Gagner program: website, various actions during the Défi sportif (good food kiosk, Défi sportif school component course, toolbox, web diffusion...), as as as the Choisir de Gagner ${ }^{4}$ tour in schools.

The launch of the new website in December 2013 has a "youth" as well as an "adult" component. Capsules and tools have been put online since then. According to the interviews, the site goes hand in hand with the growing magnitude of Choisir de Gagner over the years.

The tools that were created from the Choisir de Gagner project are split into five categories: publications; conferences and presentations; training workshops; meetings / brainstorming sessions and round tables; community networks.

Here are some examples of these tools. With regard to "publications", several scientific articles and guidebooks written by the UQTR research team in charge of the evaluation of the project, may be found: AlterGo's annual report, grids and guides regarding accessibility, etc. As for

\footnotetext{
${ }^{4}$ Choisir de Gagner's tour is part of their project. Its goal is to raise awareness of young people with functional limitations with regard to a healthy lifestyle. This is, therefore, an opportunity to offer activities to these young people and to show them how to eat well
}

"conferences and presentations", several conference organized by UQTR, among others, Quebec en Forme's annual meeting, as well as the various conferences related to the organization's mission. The "training workshops" that were given were related to universal accessibility, accessibility to events, accessible communication, integration of people with disabilities, etc. Among the related tools "meetings, brainstorming and round tables", we note the various meetings with partners such as rehabilitation centres, advisory committees, regional associations, etc. With regard to the tools related to "communities of practice", we find the Choisir de Gagner meeting, inclusive sports tours, school sports events participating in the Défi sportif and awareness events.

According to the study's results, the means of disseminating these tools that the Choisir de Gagner team favours are more technological, such as the Internet, social media, e-mails, and webinars. Other more traditional mediums are also used for the dissemination of knowledge such as letters, telephone calls or posters. Certain respondents $(20 \%)$ still prefer one-on-one exchanges (visits, tours, meetings).

Acceptance of tools

In the evaluation of the transfer of knowledge process, the acceptance of the tools stage was studied according to the level of knowledge of these tools and their context of use.

Respondents were aware of several known "publications", especially the different guides and research reports (23). The best-known was the checklist for the preparation of the Défi sportif (71.4\%). The scientific articles and professionals produced by the UQTR research team are not as well-known by the respondents. However, several did show an interest in learning about these publications.

Respondents (between $40 \%$ and 60\%) are aware of several "conferences/presentations", notably the webinar on nutrition, Québec en forme's annual meeting, the accessible cities'

and have an active life; it's also for them. Therefore, the tour offers healthy activities, initiation to sports, information sessions and also in the schools, organizations or rehabilitation centres who work with children aged 5 to 21 with functional limitations (22). 
meeting and the UQTR conference with regard to defining factors.

The majority of "training workshops" that Choisir de Gagner proposed is "very wellknown" by respondents (between 28.6\% and $47.4 \%$ ). This includes training on universal accessibility, accessibility to events, accessible communications, workshops on nutrition and training with regard to the integration of disabled people. The nutrition workshop dealing with specific nutrition concerning Autism Spectrum Disorder (ASD) (63.1\%) and the awarenessraising meeting of local partners of healthy lifestyles is less well-known (little or not at all) by respondents $(50 \%)$.

Brainstorming or round table sessions are generally known by respondents. With regard to community practices, most respondents were aware, from near or far, of the Défi sportif events related to them. Therefore, $85 \%$ of respondents knew about the Choisir de Gagner conference and $76.2 \%$ were aware of school sports events which take place at the Défi sportif.

Adoption and use of tools

The adoption and use of tools are strategies for the appropriation of knowledge during their transfer. In the study carried out, knowledge was studied through the frequency of their use. Given that some respondents did not know about some of the tools offered by Choisir de Gagner, the response rate for "Not Applicable" remains high.

Several publications are sometimes or rarely used by respondents, especially the UQTR guide (18.8\%), as well as the Go Quizz (20\%). Other publications such as the report on deciding factors, the Tool Box (25\%), social media (25\%), the analysis checklist for Universal Accessibility (18.8\%), and the guide regarding accessible communication (18.8\%) are also used. The scientific and professional articles produced by the UQTR research team are used by respondents (between $6.3 \%$ and $31.3 \%$ ), as well as documents regarding specific clienteles (between $12.5 \%$ and $31.3 \%$ ).

We noted that very few participated in the conferences and presentations suggested by Choisir de Gagner. Only the UQTR conference on deciding factors and the one given by the Quebec Association for social integration were sometimes attended by the respondents.

As well, several training workshops were attended by some (between sometimes and always). Another $18.8 \%$ indicated that they never participate in training with regard to accessible communication, nutritional workshops and meetings on awareness of local partner groups (RLP).

We also note that brainstorming and roundtable meeting as well as community practice groups were never or rarely attended by the respondents (between $12.5 \%$ and $37.5 \%$ ).

Other tools that may be useful for interventions with youth with disabilities and their families were identified by respondents. They want more practical guides for parents; simple practice sheets; extracurricular activities which involve sports; a bank of activities and adapted sports, etc.

Many tools are underutilized or even unused by Choisir de Gagner's select partners. These include lectures and presentations and training workshops or brainstorming/round table activities. Nevertheless, respondents mentioned their desire to learn more about the tools.

Satisfaction with regard to the tools

The final aspect of the evaluation of strategies for adoption, appropriation and use of knowledge is the level of user satisfaction with the tools.

The conferences and presentations, training workshops, brainstorming and round table sessions were appreciated by the users/participants, especially the webinar on nutrition, as well as the events aimed at creating a community of practice.

Appreciation of the benefits of the Choisir de Gagner project

In order to complete the results regarding the transfer of knowledge, respondents were asked to explain the main benefits of the Choisir de Gagner project.

According to respondents, the main benefits of Choisir de Gagner are positive, for the young people (physical health, motivation, etc.), but also for the organizations involved (number, mobilization, etc.). Consequently, the development of the tools suggested by Choisir de Gagner allowed for the improvement of programs offered in schools and its environment, in terms of quality and quantity of programs and to better equip physical education teachers. Families were more involved due to raised awareness throughout the Choisir de Gagner project. 
Finally, the different tools developed by Choisir de Gagner seem, according to the respondents, to make young people and their families more aware of a healthy lifestyle.

\section{DISCUSSION}

Some paths emerge in light of the obstacles and conditions identified from Mintzberg (8) and Bergeron's (6) framework analysis. This framework made it possible to establish an organizational diagnosis by examining the links existing between the parties and thus being able to understand its functionality.

First, we note the central role of the hierarchical line within an organization. More specifically, we have seen that the 'management capacity' component was of the greatest concern within the organization being studied. We refer here to the decision-making process that could be simplified, the role of each employee and the organizational chart that could be specified, and the organizational and planning structure of the stakeholders' time that could be reviewed on an annual basis.

In addition, we are referring to communication within the operational centre and the strategic summit, as well as between them (line of command) that could be improved. Adjustments were made to this organizational component of the process and several successes were unveiled during the second evaluation.

The results indicate to what extent organizational culture and entrepreneurship (10) as well as the management value integrating employees in the process (12) affect organizational effectiveness.

Lingering on each of the stages of the process of transfer of knowledge

In the framework, seven stages were identifies seven in the process of the transfer of knowledge $(18,19)$. Thus, as the evaluation of strategies of the appropriation of tools within the Choisir de Gagner project shows that knowledge of the tools still needs to be developed, this use needs to be promoted in order to satisfy a greater number of users. Perceived benefits from the project, therefore, would be better. Beyond the transfer of knowledge, it becomes relevant for the managers of organizations to understand all the stages of Knowledge management processes (13).

Explicit knowledge leading to tacit knowledge
The tools that were developed and disseminated by the Choisir de Gagner project and its partners provide explicit types of knowledge to the actors involved, in particular, the tools facilitating exchanges such as symposia, meetings, round tables and events. This knowledge, in turn, generates tacit knowledge when it favours the evolution of judgment, knowhow, and the participants' values (17). However, tacit knowledge has not been the subject of this study, particularly since it remains difficult to measure because of its intangibility (15). Nevertheless, these two types of knowledge remain essential in communities of practice and learning.

Tools for a two-way, dynamic process

The multiple tools developed and disseminated by the Choisir de Gagner project generate a three-way dynamic between researchers, knowledge producers and users (17). This dynamic, which will be maintained and strengthened, improves the collaborative relationships between the parts of the internal and external environments of the organization. The involvement of all partners remains essential in the transfer of knowledge process, especially (20).

Satisfactory tools, however little known

The main objective of Choisir de Gagner consists of sensitizing young people with a functional limitation to healthy lifestyles and to promote universal accessibility to Quebec en forme partners.

It is, therefore, important to make knowledge available and accessible (15) and the far-reaching actions by regularly monitoring with the partners to check if the tools and documents produced by Choisir de Gagner have contributed to the evolution of their methods of intervention and, more generally, their practices. At the same time, this monitoring would make it possible to inform these players of the updating of certain data or the production of new tools. In fact, several tools remain little-known by the respondents who emphasize their interest in knowing them.

\section{CONCLUSION}

Each organization has its own ideology and mission. Choisir de Gagner's mission is difficult to dissociate from AlterGo and Défi sportif's mission, which created confusion, particularly 
with regard to human resources. Choisir de Gagner is a power tool to raise awareness among Quebec's population and to improve Quebec's young people's quality of life on a daily basis, beyond an event that is confined to one event.

Several dimensions in the operating of the Choisir de Gagner project have been improved since the first evaluation in 2012-2013. The decision-making process seems clearer for all (organizational chart); the understanding of the project's mandate and everyone's roles seems to be shared, communication between all players seems more efficient and fluid and the planning of tasks also seems more efficient.

The team consolidated its achievements and mobilized partners from the region. This initiative, which focused on the healthy lifestyles of young people with functional limitations, benefited young people, their families and society as a whole. Sensitization to the healthy lifestyles of young people with a functional limitation and the promotion of universal accessibility to the actors in the environment must certainly continue beyond the Choisir de Gagner project.

The knowledge produced helps clarify the practice and further the reflection of many actors involved and concerned about the quality of life of these young people. They also captured the importance of human resources throughout the organization. However, a limitation of this knowledge that is produced is the low level of respondents to the questionnaire that allows the carrying out of the knowledge transfer analysis. This low response may be justified by the season in which the data collection occurred (June). Nevertheless, the majority of respondents share the same opinion for many of the questions asked in the questionnaire. This allows us to assert that the analyses presented in this article may be considered valid and may be used to make some improvements in the stages of knowledge transfer targeted by this study. It should also be noted that the majority of respondents are stakeholders, the primary beneficiaries of the tools developed, which thus reduces the risk of bias.

\section{APPLICABLE REMARKS}

- Within an organization, the hierarchy between management and employees plays a major role. It is important to implement a decision-making process in order to make each person's role clear and understandable.

- Sound and effective communication with the operational center (stakeholders and coordinators), within the strategic summit (managers), and between the two (line of command), remains fundamental in any organization. It is relevant to provide follow-up.

- It is important to make available and accessible the knowledge developed within the organization, especially in order to improve action. Respect for each step of the transfer of knowledge process remains essential.

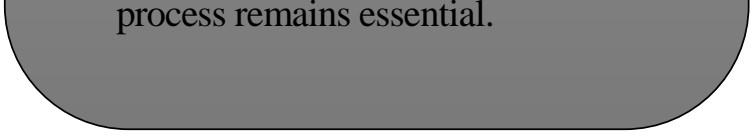

\section{FUNDING AND ACKNOWLEDGMENTS}

This work is part of the project Choisir de Gagner, put forward by Altergo, a community organization for people with disabilities in Montréal, Québec, Canada. It was supported by Québec en Forme.

\section{REFERENCES}

1. Institut de la statistique du Québec. 2013 Institut de la statistique Report : Enquête québécoise sur les limitations d'activités, les maladies chroniques et le vieillissement 2010-2011. Utilisation des services de santé et des services sociaux des personnes avec incapacité, volume 2. Québec, Canada : Gouvernement du Québec, 2013.

2. Institut de la statistique du Québec. 2012 Institut de la statistique Report : L’enquête québécoise sur la santé des jeunes du secondaire 2010-2011. Tome 1 Le visage des jeunes d'aujourd'hui : leur santé physique et leurs habitudes de vie. Québec, Canada : Gouvernement du Québec, 2012.

3. Altergo; c2016 [2016 17 september]. Available from : http://www.altergo.ca/fr/AlterGo.
4. Défi
sportif
Altergo;
c2016
[2016
17
september].
Available
from :

http://www.defisportif.com/fr/cdg/evenements.php.

5. Québec en forme; c2016 [2016 17 september]. Available from: http://www.quebecenforme.org/apropos/mission.aspx. 
6. Bergeron PG. La gestion dynamique: concepts, méthodes et applications. 4th ed: Les Éditions de la Chenelière inc.; 2006. $653 \mathrm{p}$.

7. Posavac EJ, Carey RG. Program evaluation: Methods and case studies. 7th ed: Pearson Prentice Hall; 2007. 336 p.

8. Mintzberg H. Mintzberg on management: Inside our strange world of organizations. Free Press, Collier Macmillan Publishers; $1989.418 \mathrm{p}$.

9. Morgan G. Images de l'organisation. Les Presses de l'Université Laval; 1999. 498 p.

10. Kalateh Seifari M, Amoozadeh Z. The Relationship of Organizational Culture and Entrepreneurship with Effectiveness in Sport Organizations. Annals of Applied Sport Science. 2014; 2(3): 51-60.

11. Livian YF. Organisation, théories et pratiques. 2th ed ; Éditions Dunod; 2001. 322 p.

12. Kerwin S, Maclean J, Bell-Laroche D. The Mediating Influence of Management by Values in Nonprofit Sport Organizations. Journal of Sport Management. 2014; 28(6): 646-56.

13. Ashouri T, Boroumand M. R. The Relationship between Knowledge Management and the Process of Entrepreneurship in Sport Organizations. Annals of Applied Sport Science. 2014; 2(3): 41-56.

14. Faye C, Lortie M, Desmarais L. 2007 Réseau de recherche en santé et en sécurité du travail du Québec Report : Guide sur le transfert des connaissances à l'intention des chercheurs en santé et sécurité du travail. Québec, Canada : Réseau de recherche en santé et en sécurité du travail du Québec, 2007.

15. Syed Omar Sharifuddin SI, Fytton R. Knowledge management in a public organization: A study on the relationship between organizational elements and the performance of knowledge transfer. Journal of Knowledge Management. 2004;8(2):95-111.

16. Zarinpoush F, Von Sychowski S, Sperling J. 2007 Imagine Canada Report : Transfert et échange efficaces de connaissances : un cadre de travail à l'intention des organismes sans but lucratif. Ontario, Canada : Imagine Canada, 2007.

17. Raymond L. 2009 Laboratoire de recherche sur la dynamique du transfert des connaissances de l'Université de Sherbrooke Report : Coffre à outils sur le transfert des connaissances. Une approche proactive. Québec, Canada : Laboratoire de recherche sur la dynamique du transfert des connaissances (LRTDC) de l'Université de Sherbrooke, 2009.

18. Institut national de santé publique du Québec. 2009 Institut national de santé publique Report: Animer un processus de transfert des connaissances. Bilan des connaissances et outil d'animation. Direction de la recherche, formation et développement. Québec, Canada : Gouvernement du Québec, 2009.

19. CSSS de la Vieille-Capitale, Université Laval. 2015 Bibliothèque et Archives nationales du Québec Report : Cadre de référence en transfert de connaissances pour leurs utilisations judicieuses et le soutien à l'innovation. Québec, Canada : Bibliothèque et Archives nationales du Québec, 2015.

20. Green WL, Ottoson MJ, Garcia C, Hiatt AR. Diffusion theory and knowledge dissemination, utilization, and integration in public health. Annual Review of Public Health. 2009;30(1):151-74.

21. Harvey JF. Comment favoriser le partage des connaissances? Le cas des communautés de pratiques pilotées. Gestion. 2004;35(4):73-80.

22. Choisir de Gagner; c2016 [2016 21 september]. Available from : http://choisirdegagner.com.

23. Extenso; c2016 [2016 28 september]. Available from : http://www.extenso.org/a-propos-d-extenso/. 